\title{
ARTICLE
}

Received 27 Jun 2012 | Accepted 20 Nov 2012 | Published 27 Dec $2012 \quad$ DOl: 10.1038/ncomms2325

\section{Activity of the mitochondrial calcium uniporter varies greatly between tissues}

Francesca Fieni ${ }^{1}$, Sung Bae Lee $e^{1,2, \dagger}$, Yuh Nung $\operatorname{Jan}^{1,2} \&$ Yuriy Kirichok ${ }^{1}$

The mitochondrial calcium uniporter is a highly selective channel responsible for mitochondrial $\mathrm{Ca}^{2+}$ uptake. The mitochondrial calcium uniporter shapes cytosolic $\mathrm{Ca}^{2+}$ signals, controls mitochondrial ATP production, and is involved in cell death. Here using direct patch-clamp recording from the inner mitochondrial membrane, we compare mitochondrial calcium uniporter activity in mouse heart, skeletal muscle, liver, kidney and brown fat. Surprisingly, heart mitochondria show a dramatically lower mitochondrial calcium uniporter current density than the other tissues studied. Similarly, in Drosophila flight muscle, mitochondrial calcium uniporter activity is barely detectable compared with that in other fly tissues. As mitochondria occupy up to $40 \%$ of the cell volume in highly metabolically active heart and flight muscle, low mitochondrial calcium uniporter activity is likely essential to avoid cytosolic $\mathrm{Ca}^{2+}$ sink due to excessive mitochondrial $\mathrm{Ca}^{2+}$ uptake. Simultaneously, low mitochondrial calcium uniporter activity may also prevent mitochondrial $\mathrm{Ca}^{2}+$ overload in such active tissues exposed to frequent cytosolic $\mathrm{Ca}^{2+}$ activity.

${ }^{1}$ Department of Physiology, University of California, San Francisco, UCSF Mail Code 2140, Genentech Hall Room N272F, 600 16th Street, San Francisco, California 94158, USA. ${ }^{2}$ Howard Hughes Medical Institute, Department of Physiology, University of California, San Francisco, Room 484E, 1550 4th Street, San Francisco, California 94158, USA. †Present address: Department of Brain Science, Daegu Gyeongbuk Institute of Science and Technology, Daegu 711-873, Korea. Correspondence and requests for materials should be addressed to Y.K. (email: yuriy.kirichok@ucsf.edu). 
M itochondrial $\mathrm{Ca}^{2+}$ uptake has long been recognized as instrumental in cellular physiological and pathophysiological conditions ${ }^{1-3}$. It controls the rate of mitochondrial ATP production ${ }^{4,5}$, shapes cytosolic $\mathrm{Ca}^{2+}$ signals in heart and other tissues ${ }^{6-10}$, modulates the contraction-relaxation cycle of skeletal muscle ${ }^{11,12}$, regulates immunological synapses ${ }^{13}$, and is involved in cell death ${ }^{1,14,15}$. Cytosolic $\mathrm{Ca}^{2+}$ influx into the mitochondrial matrix is mediated primarily by the mitochondrial calcium uniporter $(\mathrm{MCU})^{10,16,17}$. Patch-clamp studies in vesicles of the native inner mitochondrial membrane (IMM, mitoplasts) have demonstrated that the MCU is a highly selective $\mathrm{Ca}^{2+}$ channel with unique properties ${ }^{18}$. Functional characterization of the MCU has been followed by a search for molecular candidates, and to date two molecules, MICU1 and MCU, have been shown to be important for the MCU activity ${ }^{19-22}$.

Mitochondrial $\mathrm{Ca}^{2+}$ uptake has been primarily studied indirectly using ion flux assays in suspensions of isolated mitochondria and by calcium imaging in intact cells. These studies have led to the identification and characterization of the phenomenon of mitochondrial $\mathrm{Ca}^{2+}$ uptake in vitro ${ }^{17,23}$ and demonstrated that this uptake occurs under physiological conditions in intact cells despite the low transport affinity of MCU for $\mathrm{Ca}^{2+}$ (refs 24,25). However, these methods do not measure MCU activity directly; thus, mitochondrial potential $\left(\Delta \Psi_{\mathrm{m}}\right)$, matrix $\mathrm{pH}$, and ion gradients across the IMM cannot be accurately controlled ${ }^{17,23,25}$.

Therefore, it is not clear whether mitochondrial $\mathrm{Ca}^{2+}$ uptake mediated by the MCU is the same among different tissues and whether any differences can influence the physiology of these tissues. Scarce evidence for the tissue heterogeneity of $\mathrm{Ca}^{2+}$ uptake mediated by the MCU exists ${ }^{26}$, and it is still generally assumed that the activity of the $\mathrm{Ca}^{2+}$ conductance associated with the MCU is the same among different tissues ${ }^{27,28}$.

Here we applied the patch-clamp technique to mitoplasts isolated from a variety of excitable, as well as non-excitable mouse tissues. This method allows for the comparison of MCU activity in different tissues under tightly controlled conditions of $\Delta \Psi_{\mathrm{m}}$, $\mathrm{Ca}^{2+}$ and $\mathrm{H}^{+}$gradients across the IMM ${ }^{18}$. Unexpectedly, of all mouse tissues tested (heart, skeletal muscle, liver, kidney and brown fat), heart mitochondria manifested the lowest MCU activity. The MCU current density in heart mitochondria was 30 times smaller than that in skeletal muscle. The relevance of this evidence was further corroborated by our observation that mitochondria from the highly metabolically active Drosophila flight muscle manifests almost no MCU activity, at variance with other populations of Drosophila mitochondria, which indeed possess large current densities. Our results are the first direct evidence that the amount of $\mathrm{Ca}^{2}+$ uptake mediated by the MCU varies between tissues. The low mitochondrial $\mathrm{Ca}^{2+}$ conductance observed in tissues with a high mitochondrial volume density and that are continuously subjected to high cytosolic $\mathrm{Ca}^{2+}$ elevations, such as mouse heart and Drosophila flight muscle, is likely to be essential in having normal intracellular $\mathrm{Ca}^{2+}$ signaling, as well as protecting these active tissues from toxic mitochondrial $\mathrm{Ca}^{2+}$ overload.

\section{Results}

Mitochondrial $\mathrm{Ca}^{2+}$ current varies among mouse tissues. The unique conductance that mediates $\mathrm{Ca}^{2+}$ uptake into mitochondria was shown to be a very selective $\mathrm{Ca}^{2}+$ channel with high current density in monkey-derived COS7 cells ${ }^{18}$. In that study, the patch-clamp technique applied to mitoplasts (obtained by hypotonic shock-disruption of the outer mitochondrial membrane (OMM) of isolated COS7 cell mitochondria) was used to record $\mathrm{Ca}^{2+}$ currents carried by the $\mathrm{MCU}^{18}$. Yet, the success rate in formation of the 'whole-mitoplast' mode of the patch-clamp technique to record currents across the whole native IMM was low.

French press employed to mechanically subfractionate mitochondria was advantageous over others methods, as mitoplasts with both structural and functional integrity were obtained $^{29}$. Here we patch-clamped mitoplasts derived from French-pressed mitochondria of mouse heart, skeletal muscle, liver, kidney and brown adipose tissue. The French press protocol used to obtain vescicles of the IMM proved instrumental in increasing the yield of reliable and stable whole-mitoplast recordings from all tissues studied.

Figure 1 (see picture in the inset) shows a differential interference contrast image of a mouse heart mitoplast obtained with the French press method. In $150 \mathrm{mM} \mathrm{KCl}$ solution, mitoplasts generated with the French press method normally have a figure 8-shaped form, as the IMM protrudes through one of small ruptures in the OMM to produce a bilobed vesicle. The lobe of the mitoplast covered with remnants of the OMM (inset, red arrow) appeared optically denser (as it contained two membranes) than the lobe consisting of the IMM only (inset, white arrow). After strorage on ice for several hours, mitoplasts assumed a round shape with the remnants of the OMM attached from one side (the so-called 'cap' region). We found that the newly prepared figure 8 -shaped mitoplasts were the best choice for the formation of the whole-mitoplast mode, while the success rate in the formation of this mode with older round-shaped mitoplasts was lower.

In the whole-mitoplast configuration, the addition of $100 \mu \mathrm{M}$ $\mathrm{Ca}^{2+}$ to the bath (the cytosolic face of the IMM) induced an inwardly rectifying $\mathrm{Ca}^{2}+$ current, presumably carried by the $\mathrm{MCU}\left(I_{\mathrm{MCU}}\right) . I_{\mathrm{MCU}}$ current density greatly varied among different tissues examined (Fig. 1). $I_{\mathrm{MCU}}$ current densities measured upon stepping from $0 \mathrm{mV}$ to $-160 \mathrm{mV}$ were as follows: skeletal muscle, $58 \pm 4 \mathrm{pA} / \mathrm{pF}, n=10$; brown adipose tissue, $56 \pm 7 \mathrm{pA} / \mathrm{pF}$, $n=6$; kidney, $32 \pm 3 \mathrm{pA} / \mathrm{pF}, n=10$; liver, $25 \pm 2 \mathrm{pA} / \mathrm{pF}, n=10$; and heart, $2.1 \pm 0.6 \mathrm{pA} / \mathrm{pF}, n=8$ (Fig. 1, histogram in the lower right panel, mean \pm s.e.).

Surprisingly, $I_{\mathrm{MCU}}$ in heart mitoplasts was the lowest among all tissues and as much as 30 times smaller than that in closely related skeletal muscle. In contrast, another hallmark conductance of the IMM, the inner membrane anion channel $^{30-32}$, was present in all tissues examined (not shown) and showed no difference in activity between heart and skeletal muscle (Fig. 2).

As skeletal muscle and heart are related tissues and showed the higest and lowest $I_{\mathrm{MCU}}$ current densities, respectively, we compared the biophysical properies of $I_{\mathrm{MCU}}$ in these tissues to confirm that $I_{\mathrm{MCU}}$ has the same properties in heart and skeletal muscle and is thus mediated by the same channel.

$I_{\mathrm{MCU}}$ shares the same properties in heart and skeletal muscle. In both heart and skeletal muscle, $I_{\mathrm{MCU}}$ elicited by voltage steps was primarily time-independent (Fig. 3a) and apparently lacked $\mathrm{Ca}^{2+}$-dependent inactivation, similar to what was previously reported for $I_{\mathrm{MCU}}$ in COS7 cell mitochondria. As expected, in both tissues, $I_{\mathrm{MCU}}$ was completely blocked by $50 \mathrm{nM}$ RuR, a potent blocker of the MCU 17,18 (Fig. 3b).

As expected for the $\mathrm{Ca}^{2+}$ current, $I_{\mathrm{MCU}}$ gradually increased as $\mathrm{Ca}^{2+}$ concentrations in the bath were gradually elevated from $50 \mu \mathrm{M}$ to $1 \mathrm{mM}$ in both heart and skeletal muscle (Fig. $4 \mathrm{a}$ ). $\mathrm{Mg}^{2+}$ did not induce any $I_{\mathrm{MCU}}$ (Fig. $4 \mathrm{~b}$ ), and the current traces in the presence of $\mathrm{Mg}^{2+}$ in the bath solution were identical to the baseline (obtained in $200 \mathrm{nM} \mathrm{RuR,} \mathrm{data} \mathrm{not} \mathrm{shown).} \mathrm{The} \mathrm{addition}$ 

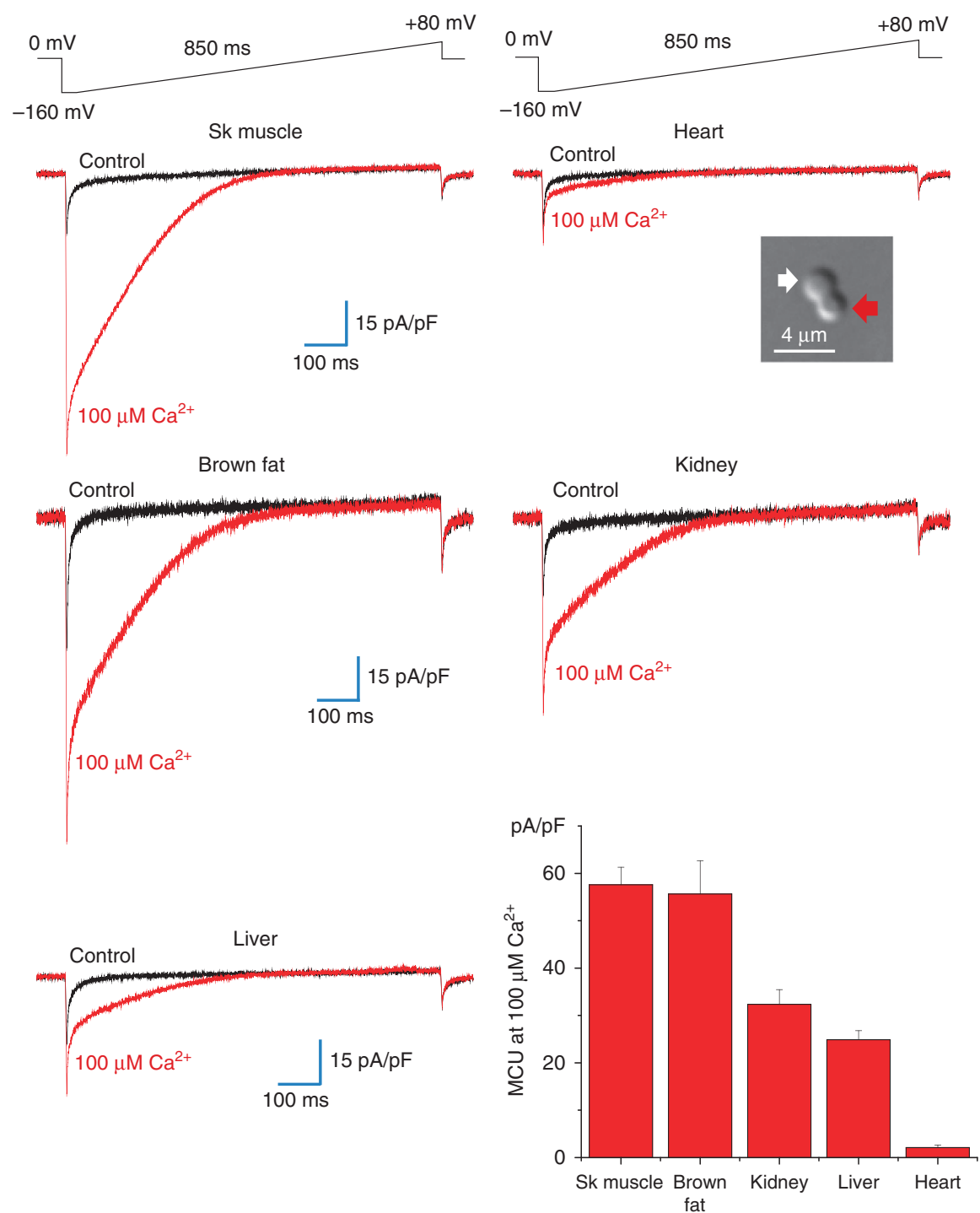

Figure 1 | Mitochondrial $\mathbf{C a}^{2}+$ conductance in different mouse tissues. Whole-mitoplast current recorded before (black traces) and after (red traces) application of $100 \mu \mathrm{M} \mathrm{Ca}^{2}+$ to the bath solution. Currents were elicited by a voltage-ramp protocol (shown above) from different mouse tissues (as indicated). Note that brown fat mitoplasts were isolated from mice deficient for uncoupling protein 1 (UCP1, see methods). Whole-mitoplast $I_{\text {MCu }}$ was normalized to the membrane capacitance $\left(C_{m}\right)$ in all tissues examined. Picture in inset, representative transmitted differential interference contrast image of a mouse heart mitoplast obtained with French press. Note the figure 8-shaped form of the mitoplast. The lobe of the mitoplast containing only the IMM was less dense (white arrow) and clearly distinguishable from the lobe covered with the OMM (red arrow). Bottom right panel: Histogram showing average $I_{\mathrm{MCu}}$ current densities in $100 \mu \mathrm{M} \mathrm{Ca}^{2}+$ in different tissues. Current amplitudes were measured at $5 \mathrm{~ms}$ after stepping from $0 \mathrm{mV}$ to $-160 \mathrm{mV}$ (see the voltage protocol). Note the low $I_{M C U}$ current density in heart compared with other tissues. Statistical data are represented as mean \pm s.e.m.

of $\mathrm{Ba}^{2+}$ to the bath induced $I_{\mathrm{MCU}}$, but the $\mathrm{Ba}^{2+}$ current was much smaller than that induced by $\mathrm{Ca}^{2+}$ (Fig. 4b,c). The permeability sequence for $\mathrm{I}_{\mathrm{MCU}}, \mathrm{Ca}^{2+} \gg \mathrm{Ba}^{2+}>\mathrm{Mg}^{2+}$, (Fig. 4c) was the same as reported for the MCU studied by indirect methods ${ }^{17,33,34}$ and by patch-clamping mitoplasts from COS7 cells $^{18}$. Notably, the $I_{\mathrm{MCU}}$ permeability sequence is unique, as most $\mathrm{Ca}^{2}+$ channels conduct $\mathrm{Ba}^{2}+$ better than $\mathrm{Ca}^{2+}$ (ref. 35).

$\mathrm{Ca}^{2+}$ channels are selective for $\mathrm{Ca}^{2+}$ due to the presence of high-affinity binding sites for $\mathrm{Ca}^{2+}$ in the pore region ${ }^{35}$. Yet, under divalent-free (DVF) conditions, monovalent ions, which have significantly lower affinity for these binding sites, can still bind within the pore and permeate the $\mathrm{Ca}^{2+}$ channels ${ }^{35}$. The monovalent current is inhibited when $\mathrm{Ca}^{2+}$ is re-added to the bath solution, as $\mathrm{Ca}^{2+}$ occupies the binding site in the pore and thus prevents monovalent ions from permeation. For plasma membrane $\mathrm{Ca}^{2+}$ channels, the inhibition of the monovalent current by $\mathrm{Ca}^{2}+$ occurs in the low micromolar range, whereas for the MCU of COS7 cells, this inhibition occurs in the low nanomolar range ${ }^{18}$. This finding identifies the MCU as the $\mathrm{Ca}^{2+}$ channel with the highest known $\mathrm{Ca}^{2+}$ selectivity. We, therefore, asked whether the MCU in mouse heart and skeletal muscle has the same high selectivity for $\mathrm{Ca}^{2+}$ over monovalent ions as the MCU in COS7 cells.

Under DVF conditions when bath and pipette solutions contained $110 \mathrm{mM} \mathrm{Na}^{+}$, we observed a quasi-linear current in both skeletal muscle and heart (Fig. 5a-c, left panels for skeletal muscle and right panels for heart throughout). This $\mathrm{Na}^{+}$current was almost completely blocked by as low as $11 \mathrm{nM}$ bath-free 

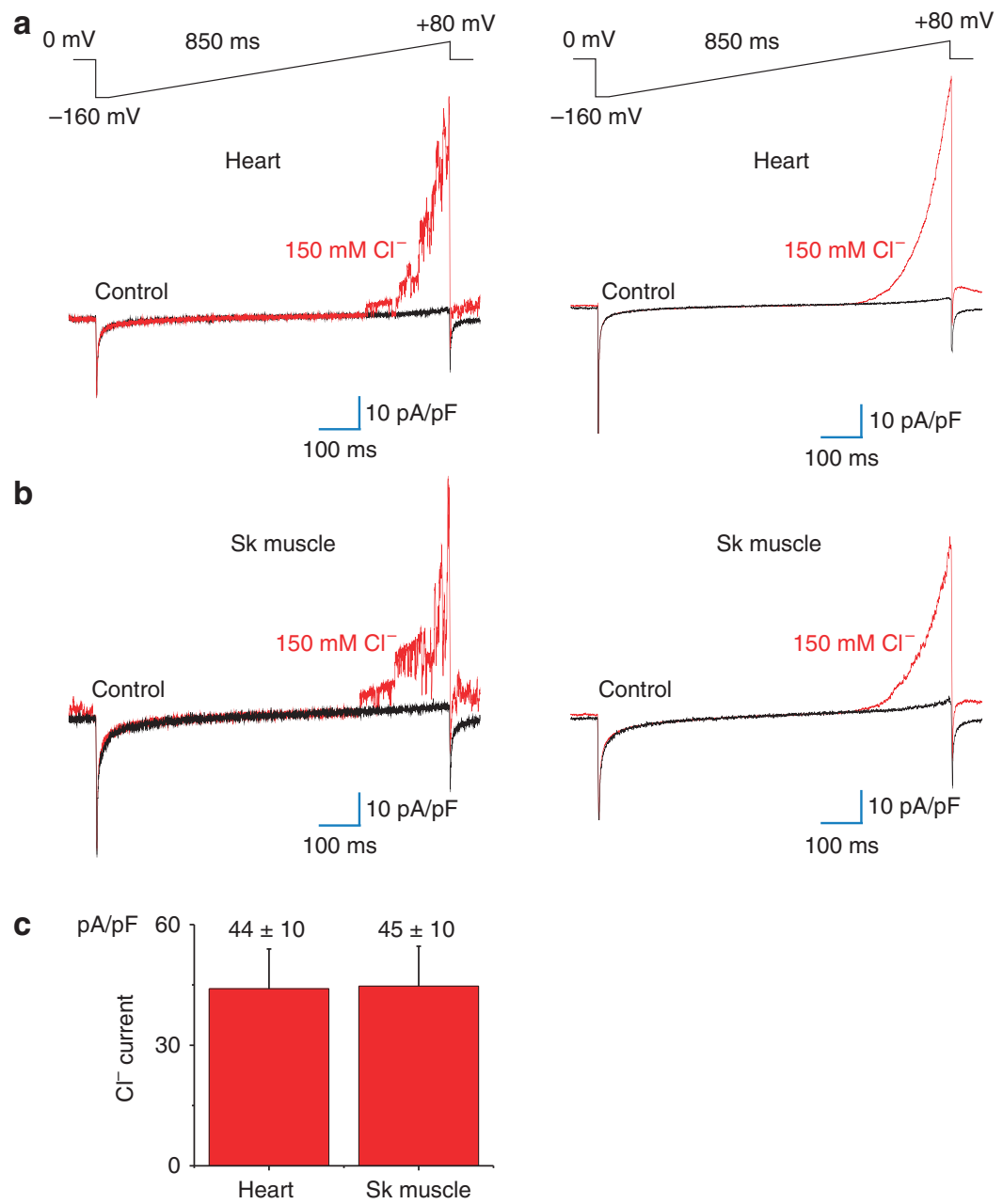

Figure 2 | $\mathbf{~ C l}^{-}$current of the IMM of heart and skeletal muscle. (a) Left panel: representative whole-mitoplast current recorded from a mouse heart mitoplast before (black traces) and after (red traces) application of $150 \mathrm{mM} \mathrm{Cl}^{-}$to the bath solution. Pipette solution contained $4 \mathrm{mM} \mathrm{Cl}{ }^{-}$. Currents were elicited by a voltage-ramp protocol (shown above). The whole-mitoplast $\mathrm{Cl}^{-}$current was normalized to the membrane capacitance $\left(C_{\mathrm{m}}\right)$. Right panel: Same experiment as in (a), but the traces represent an average of 30-50 original current traces to smooth out fluctuations of the outward $\mathrm{Cl}$ - current mediated by the large-conductance inner membrane anion channel (b) Left panel: representative whole-mitoplast current recorded from a mouse skeletal muscle mitoplast before (black traces) and after (red traces) application of $150 \mathrm{mM} \mathrm{Cl}^{-}$to the bath solution. Pipette solution contained $4 \mathrm{mM} \mathrm{Cl}{ }^{-}$. Currents were elicited by a voltage-ramp protocol (shown above). The whole-mitoplast $\mathrm{Cl}^{-}$current was normalized to the membrane capacitance $\left(C_{\mathrm{m}}\right)$. Right panel: Same experiment as in (a), but the traces represent an average of 30-50 original current traces to smooth out fluctuations of the outward $\mathrm{Cl}$ - current mediated by the large-conductance anion channel. (c) Histogram comparing average $\mathrm{Cl}^{-}$current densities in $150 \mathrm{mM} \mathrm{Cl}^{-}$in mouse heart $(n=4)$ and skeletal muscle $(n=3)$. Current amplitudes were measured at $+80 \mathrm{mV}$ (see the voltage protocol) and normalized to the $C_{\mathrm{m}}$. Statistical data are represented as mean \pm s.e.m. Sk muscle, skeletal muscle.

$\mathrm{Ca}^{2+}$, and $160 \mathrm{nM} \mathrm{Ca}^{2+}$ totally abolished it (Fig. 5a). The $\mathrm{Ca}^{2+}$-sensitive $\mathrm{Na}^{+}$current was evidently mediated by the MCU that lost its selectivity under DVF conditions ${ }^{18}$, which was further confirmed by the fact that the $\mathrm{Na}^{+}$current was completely inhibited by $200 \mathrm{nM}$ RuR (Fig. 5b). Similar to COS7 cell mitoplasts ${ }^{18}$, substitution of $\mathrm{Na}^{+}$for $\mathrm{K}^{+}$in the bath solution resulted in significantly lower monovalent current through the MCU, showing that the MCU was relatively impermeant to $\mathrm{K}^{+}$ ions, in both skeletal muscle and heart (Fig. 5c).

The amplitude of the $\mathrm{Na}^{+}$current through the MCU was dramatically lower in heart $(23 \pm 1 \mathrm{pA} / \mathrm{pF}, n=5)$ compared with skeletal muscle $(713 \pm 23 \mathrm{pA} / \mathrm{pF}, n=5)$, which correlates well with the difference in amplitude of the $\mathrm{Ca}^{2+}$ currents between these two tissues (Fig. $5 \mathrm{~d}$ ). We conclude that $I_{\mathrm{MCU}}$ shares the same biophysical properties in heart and skeletal muscle, and these properties coincide with those of $I_{\mathrm{MCU}}$ in COS7 cells ${ }^{18}$.
Thus $I_{\mathrm{MCU}}$ in heart and skeletal muscle is likely mediated by the same molecule, but heart mitochondria are endowed with dramatically lower MCU activity.

$I_{\mathrm{MCU}}$ is significantly larger in neonatal versus adult heart. An important unresolved problem in cardiac $\mathrm{Ca}^{2+}$ signalling is whether beat-to-beat elevations of mitochondrial $\left[\mathrm{Ca}^{2+}\right]$ occur in intact cardiomyocytes. Although this issue was addressed by several laboratories, a general consensus has not been reached. In a recent review, it has been noted that beat-to-beat oscillations might be developmentally regulated and occur in neonatal but not adult cardiomyocytes ${ }^{7}$. Although it has never been previously suggested, one of the specific reasons for this may be a higher $\mathrm{Ca}^{2}+$ conductance of the IMM in neonatal cardiomyocytes as compared with adult cells. 
a

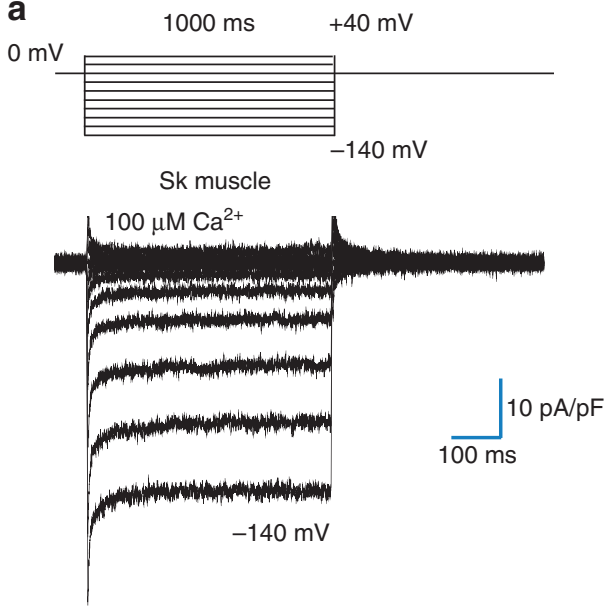

b
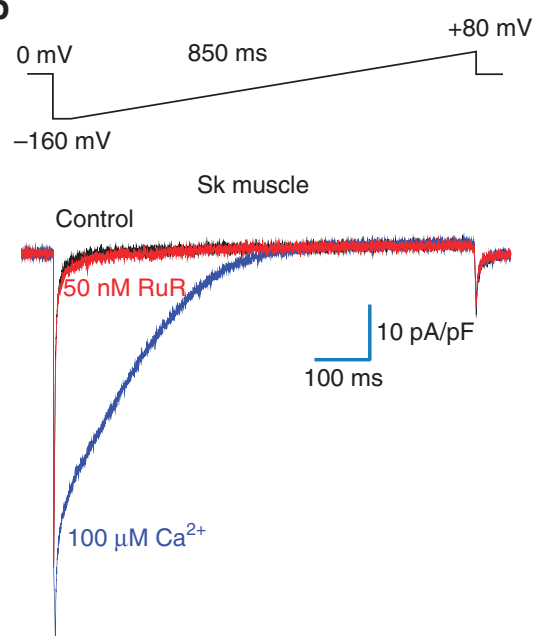

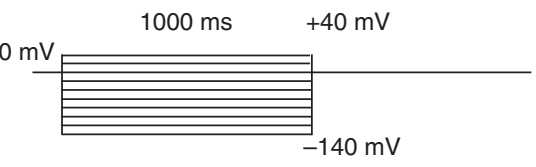

Heart

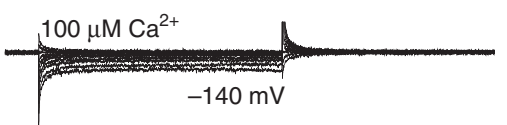

$$
100 \mathrm{~ms} 10 \mathrm{pA} / \mathrm{pF}
$$
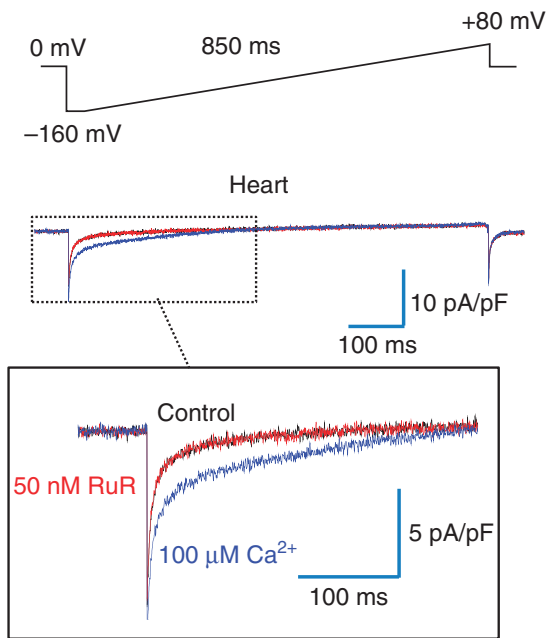

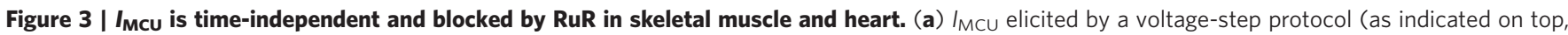
$\Delta \mathrm{V}=20 \mathrm{mV}$ ) in skeletal muscle (left panel) and heart (right panel). (b) I $\mathrm{Mcu}$ recorded in the presence of $100 \mu \mathrm{M} \mathrm{Ca}{ }^{2}+$ (blue trace) was completely inhibited by $50 \mathrm{nM}$ RuR (red trace) both in skeletal muscle (left panel) and heart (right panel). The black traces indicate the baseline recorded in the absence of $\mathrm{Ca}^{2+}$ in the bath. Currents were normalized to the membrane capacitance to compare $I_{\mathrm{MCU}}$ in heart and skeletal muscle. Voltage-ramp protocol is indicated on top. Sk muscle, skeletal muscle.

To test this hypothesis, we compared $I_{\mathrm{MCU}}$ current density in cardiac mitoplasts isolated from newborn (2-day-old) and adult ( $>3$ weeks) mice. Whole-mitoplast $\mathrm{Ca}^{2}+$ currents from 2-dayold heart were recorded using the same solutions and voltage protocols used for adult heart. Interestingly, $I_{\mathrm{MCU}}$ current density in neonatal mitoplasts measured with $100 \mu \mathrm{M} \mathrm{Ca}^{2+}$ in the bath was five times larger $(10.2 \pm 0.3 \mathrm{pA} / \mathrm{pF})$ than in adult mitoplasts $(2.1 \pm 0.5 \mathrm{pA} / \mathrm{pF}$, see Fig. 6). These results demonstrate that the IMM of the neonatal heart has significantly larger $\mathrm{Ca}^{2+}$ conductance as compared with adult heart, which may explain the age-related differences in beat-to-beat mitochondrial $\mathrm{Ca}^{2+}$ accumulation in cardiomyocytes.

Tissue heterogeneity of $I_{\mathrm{MCU}}$ in Drosophila. Similar to our findings in mouse tissues, we found a dramatic difference in the density of the mitochondrial $\mathrm{Ca}^{2+}$ current among Drosophila tissues.

We first studied $\mathrm{Ca}^{2}+$ currents in mitoplasts isolated from Drosophila flight muscle, which is of particular interest because this organ contracts at high frequencies. We obtained mitoplasts from thoraces of a Drosophila line in which the targeted mitochondrial expression of green fluorescent protein (GFP) in muscles was driven by crossing a upstream activating sequenceMitoGFP line with a muscle specific Mef2-Gal4 line (see Methods for details). Flight muscle mitochondria from this line express GFP in the matrix; hence, mitoplasts originating from it fluoresce. Drosophila thoraces were cleaned of legs to reduce contamination from leg muscle mitochondria. Figure 7 a shows a typical flight muscle GFP-fluorescent mitoplast used for patch-clamp recordings. Similar to mouse mitoplasts, Drosophila mitoplasts were obtained using the French press procedure and normally showed the same figure 8-shaped morphology (compare Figs 7a and 1 inset). The lobe that contained only the IMM was distinguishable from the optically denser lobe that was covered with the OMM and contained two membranes (Fig. 7a, white and red arrows, respectively).

Drosophila flight muscle whole-mitoplast $\mathrm{Ca}^{2}+$ currents were recorded using the same solutions and voltage protocols used for mouse mitoplasts. Interestingly, the $\mathrm{Ca}^{2}+$ current induced by the 
a

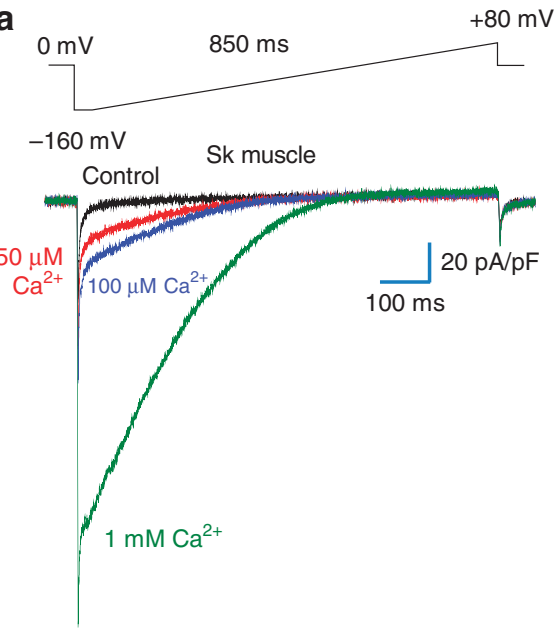

b

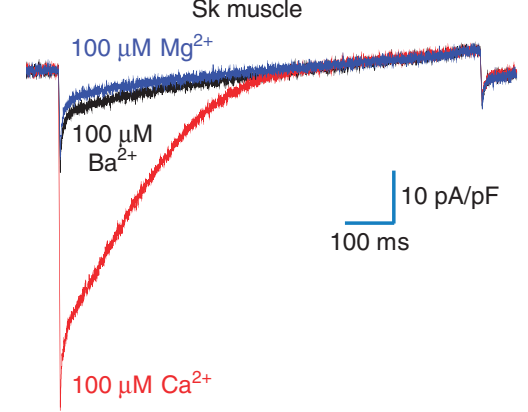

C

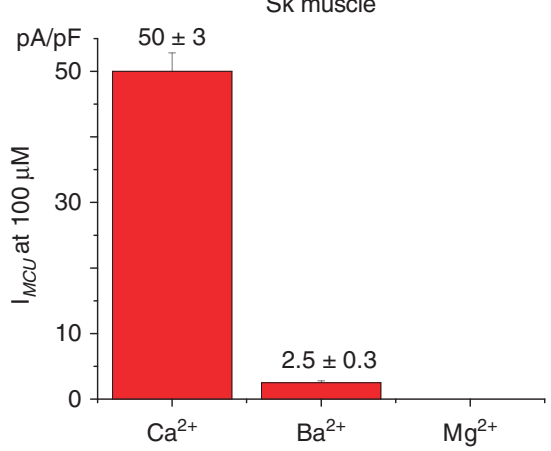

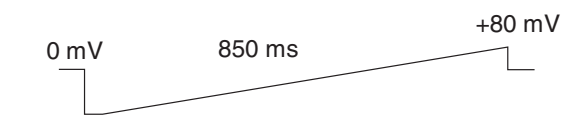

$-160 \mathrm{mV}$
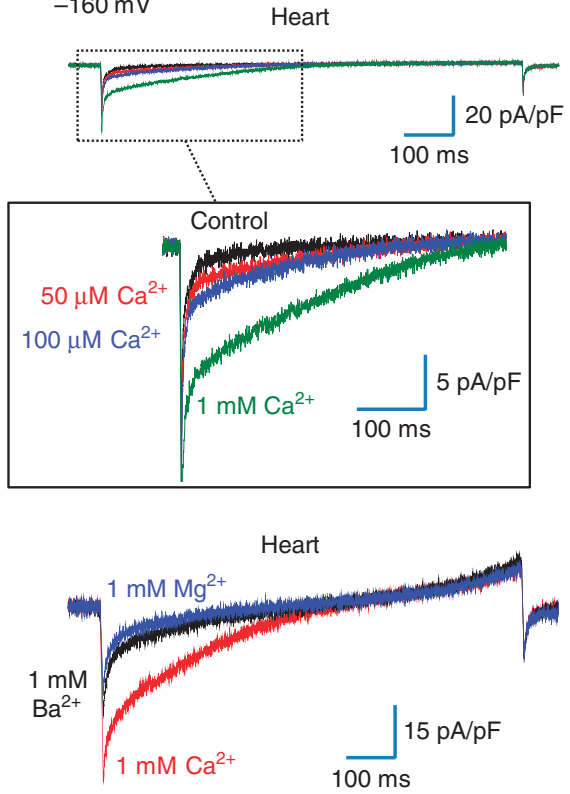

Heart

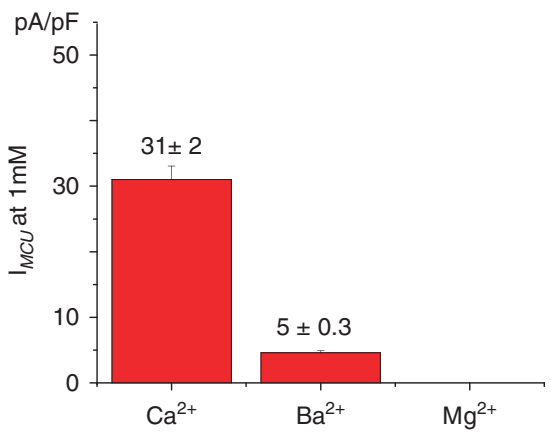

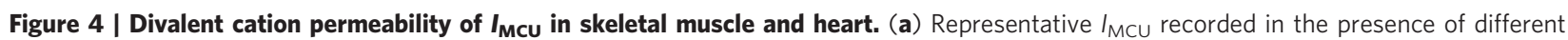
concentrations of $\mathrm{Ca}^{2+}$ in the bath: nominal $\mathrm{Ca}^{2}{ }^{+}$-free (black), $50 \mu \mathrm{M}$ (red), $100 \mu \mathrm{M}$ (blue), and $1 \mathrm{mM}$ (green). Voltage-ramp protocol is indicated on top. (b) Left panel, Representative $I_{\mathrm{MCu}}$ recorded from a skeletal muscle mitoplast in the presence of $100 \mu \mathrm{M} \mathrm{Ca}{ }^{2+}$ (red trace), $\mathrm{Ba}^{2+}$ (black trace), and $\mathrm{Mg}^{2}+$ (blue trace). Right panel, Representative $I_{\mathrm{MCu}}$ recorded from a heart mitoplast in the presence of $1 \mathrm{mM} \mathrm{Ca}^{2+}\left(\right.$ red trace), Ba ${ }^{2+}($ black trace), and $\mathrm{Mg}^{2+}$ (blue trace). (c) Histograms of the relative permeability of $I_{\mathrm{MCu}}$ to $\mathrm{Ca}^{2+}, \mathrm{Ba}^{2+}$ and $\mathrm{Mg}^{2+}$ in skeletal muscle $(n=4$, left panel) and heart $(n=4$, right panel). Current amplitudes were measured at $5 \mathrm{~ms}$ after stepping from 0 to $-160 \mathrm{mV}$ (see the voltage protocol in b). Statistical data are represented as mean \pm s.e.m. Sk muscle, skeletal muscle.

gradual elevation of $\mathrm{Ca}^{2+}$ in the bath from $100 \mu \mathrm{M}$ to $5 \mathrm{mM}$ was barely detectable (Fig. 7b, left panel). Similar to the MCU current observed in mammalian mitoplasts, this small $\mathrm{Ca}^{2}+$ current was RuR sensitive (Fig. 7b, left panel).

In contrast, when we specifically selected non-GFP mitoplasts that originated from tissues other than flight muscle of the Mef2 $>$ MitoGFP flies, we were able to record robust whole-mitoplast RuR-sensitive $\mathrm{Ca}^{2}+$ currents. Figure $7 \mathrm{~b}$ shows a representative $\mathrm{Ca}^{2+}$ current recorded from one such mitoplast. Interestingly, the density of the $\mathrm{Ca}^{2}+$ current recorded from this particular mitoplast at $100 \mu \mathrm{M} \mathrm{Ca}^{2+}(175 \mathrm{pA} / \mathrm{pF})$ was significantly higher than that in any other mouse tissue examined (Fig. 1).
Overall, we recorded 31 Drosophila mitoplasts. Those mitoplasts originating from the flight muscle $(n=21)$ consistently showed a very-low $\mathrm{Ca}^{2+}$ current both in $100 \mu \mathrm{M} \mathrm{Ca}^{2+}(0.4 \pm 0.2 \mathrm{pA} / \mathrm{pF}$, $n=8)$ and in $1 \mathrm{mM} \mathrm{Ca}^{2+}(3.9 \pm 0.1 \mathrm{pA} / \mathrm{pF}, n=13)$. Among the 10 mitoplasts derived from tissues other than flight muscle, six showed a $\mathrm{Ca}^{2+}$ current significantly higher than that observed in flight muscle and four showed a very small $\mathrm{Ca}^{2+}$ current. The six Drosophila mitoplasts with high $\mathrm{Ca}^{2+}$ currents had very different values for current density (from 15 to $175 \mathrm{pA} / \mathrm{pF}$ in $100 \mu \mathrm{M} \mathrm{Ca}^{2+}$ and from 11 to $800 \mathrm{pA} / \mathrm{pF}$ in $1 \mathrm{mM} \mathrm{Ca}^{2+}$ ). The densities of the mitochondrial $\mathrm{Ca}^{2}+$ currents from Drosophila flight muscle and other tissues are compared in Fig. 7c. 

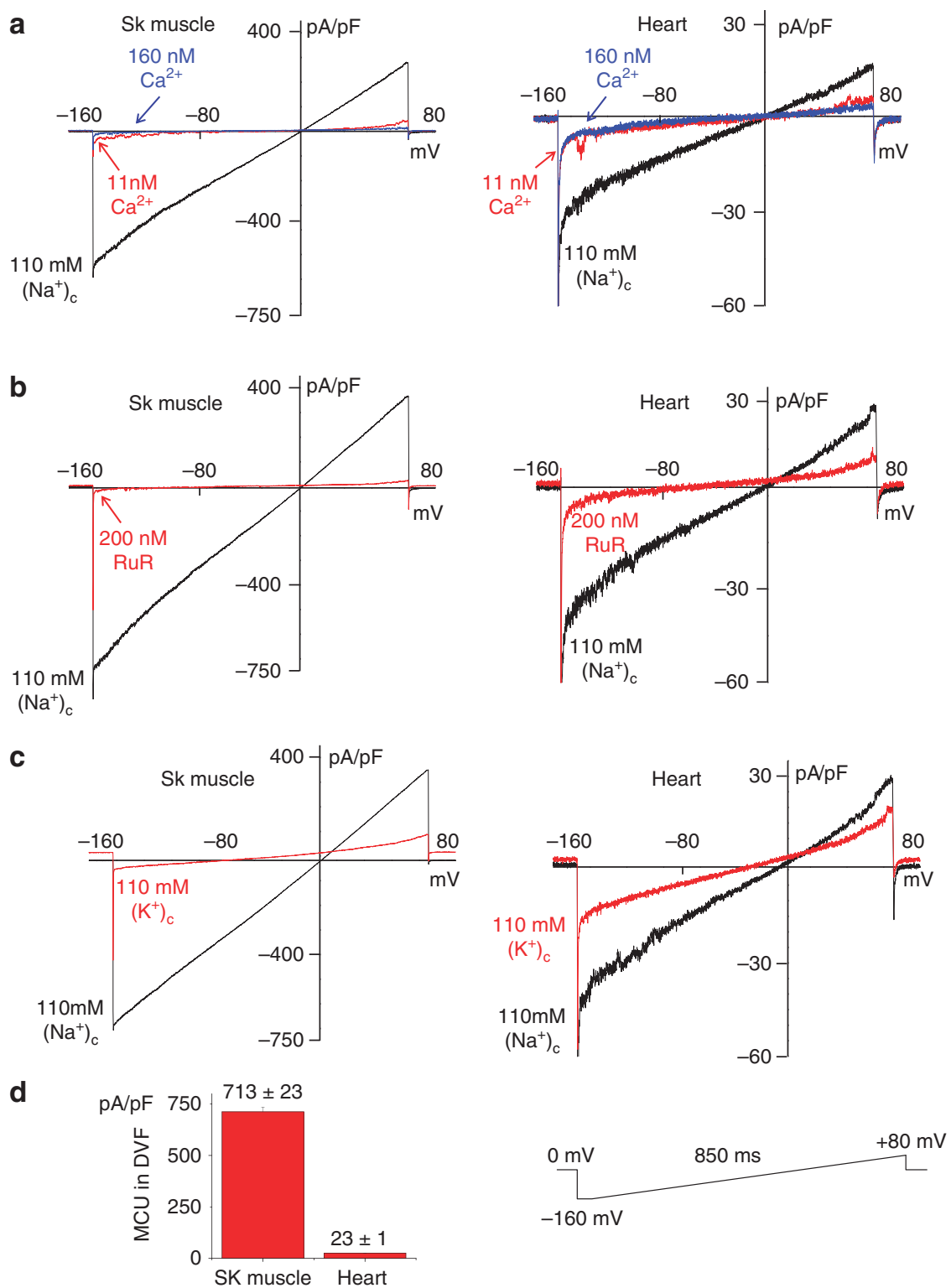

Figure $\mathbf{5} \mid \boldsymbol{I}_{\mathbf{M C u}}$ is carried by $\mathbf{N a}^{+}$under DVF conditions in skeletal muscle and heart. (a) $\mathrm{Na}^{+}$current through the MCU under DVF conditions (black trace), and in the presence of either $11 \mathrm{nM}$ (red trace) or $160 \mathrm{nM}$ (blue trace) free $\mathrm{Ca}^{2+}$ in the bath solution. Skeletal muscle (left panel), heart (right panel). Currents were normalized to membrane capacitance. The voltage protocol is shown in bottom of the figure. (b) The $\mathrm{Na}^{+}$current through the MCU before (black trace) and after (red trace) the addition of $200 \mathrm{nM}$ RuR to the bath solution. (c) Monovalent current through the MCU in symmetrical $110 \mathrm{mM} \mathrm{Na}^{+}$(black trace) and after replacement of bath $\mathrm{Na}^{+}$with $\mathrm{K}^{+}$(red trace). (d) Histogram showing average densities of $\mathrm{Na}^{+}$current through the MCU in skeletal muscle $(n=5)$ and heart $(n=5)$. Current amplitudes were measured at $5 \mathrm{~ms}$ after stepping the membrane from 0 to $-160 \mathrm{mV}$ (see the voltage protocol). Statistical data are represented as mean \pm s.e.m. Sk muscle, skeletal muscle.

In spite of the fact that the amplitude of the $\mathrm{Ca}^{2+}$ current was extremely low in flight muscle mitoplasts, these mitoplasts had very large $\mathrm{Cl}^{-}$current (Fig. 8) with the mean current density of $161 \pm 6 \mathrm{pA} / \mathrm{pF}$ at $+80 \mathrm{mV}, n=4$. This is the first observation of the existence of a mitochondrial $\mathrm{Cl}^{-}$conductance in Drosophila.

Therefore, as seen for mouse tissues, Drosophila tissues display significant differences in the mitochondrial $\mathrm{Ca}^{2+}$ current density. RuR-sensitive $\mathrm{Ca}^{2+}$ uptake into mitochondria isolated from the Drosophila-derived S2 cell line has recently been demonsrated ${ }^{36}$. This uptake and the RuR-sensitive $\mathrm{Ca}^{2+}$ currents recorded from Drosophila mitoplasts are both likely to be mediated by a Drosophila homologue of the mammalian MCU.

\section{Discussion}

The phenomenon of MCU-mediated $\mathrm{Ca}^{2+}$ uptake is one of the most interesting aspects of mitochondrial physiology. From its original discovery in the early 1960s (refs 37,38 ), this process was studied primarily with biochemical (ion flux studies) and optical (fluorescent proteins and indicators) methods, in either suspensions of isolated mitochondria or intact cells $s^{3,17,23,25}$. Although these methods identified the phenomenon of mitochondrial $\mathrm{Ca}^{2+}$ uptake and provided its initial characterization, they did not allow for the reliable control of experimental conditions, and there have been significant variations in the rate of mitochondrial uptake measured in the 
a
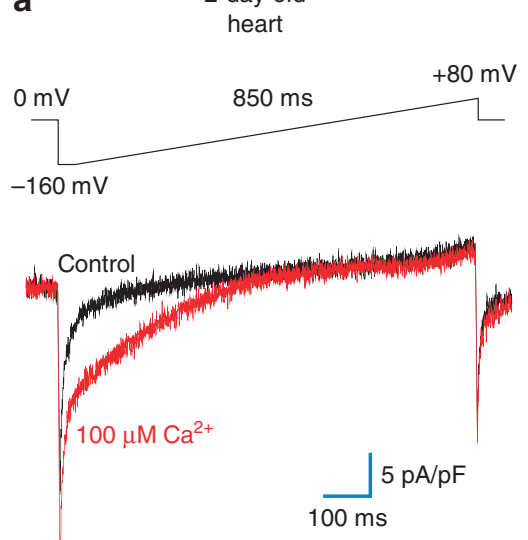

b

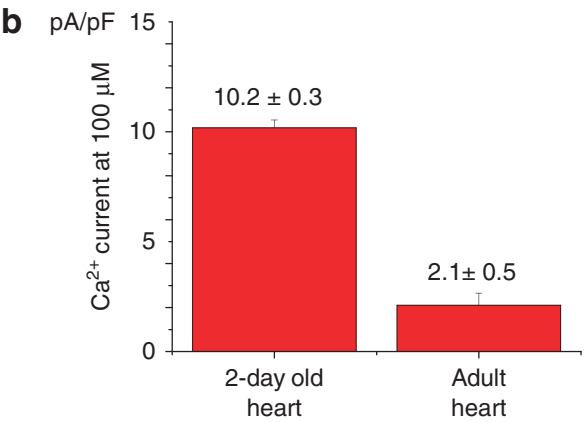

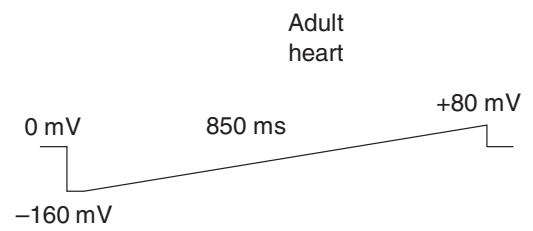

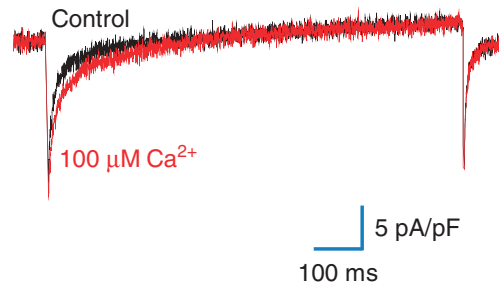

Figure 6 | $\boldsymbol{I}_{\mathbf{M C u}}$ current density is significantly larger in neonatal compared with adult heart. (a) Left panel, Representative $I_{\text {MCU }}$ elicited in the presence of $100 \mu \mathrm{M} \mathrm{Ca}^{2}+$ (red traces) in a cardiac mitoplast isolated from a 2-day-old mouse. The black trace indicates the baseline recorded in the absence of $\mathrm{Ca}^{2+}$ in the bath. Right panel, the same experiment performed with a cardiac mitoplast isolated from a 4-week-old (adult) mouse. Currents were elicited by a voltage-ramp protocol shown above. Whole-mitoplast $I_{\mathrm{MCU}}$ was normalized to the $C_{\mathrm{m}}$. (b) Histogram comparing average $I_{\mathrm{MCU}}$ current densities in 2 day-old $(n=5)$ and adult heart $(n=8)$. Current amplitudes were measured at $5 \mathrm{~ms}$ after stepping from 0 to $-160 \mathrm{mV}$ (see the voltage protocol) and normalized to the $C_{m}$. Statistical data are represented as mean \pm s.e.m.

same tissues by different labs ${ }^{17,23,25}$. Reliable comparisons of mitochondrial $\mathrm{Ca}^{2+}$ uptake between different tissues have been difficult, and rare reports on the tissue-specific differences in MCU activity ${ }^{26}$ have also been largely overlooked. Therefore, it was eventually concluded that mammalian mitochondria have a high rate of $\mathrm{Ca}^{2+}$ uptake, and the MCU was described as a "highcapacity' $\mathrm{Ca}^{2+}$ transport mechanism ${ }^{17,23}$. Indeed, in many tissues, mitochondrial $\mathrm{Ca}^{2+}$ uptake potently affects cytosolic $\mathrm{Ca}^{2+}$ transients and causes a significant elevation of $\mathrm{Ca}^{2+}$ in the mitochondrial matrix ${ }^{10,24}$. Thus, the present consensus in the field is that all mammalian mitochondria are endowed with approximately the same MCU activity and the same high ability to accumulate $\mathrm{Ca}^{2+}$.

The demonstration that whole-IMM and unitary MCU currents can be recorded with the patch-clamp technique ${ }^{18}$ overcame the technical limitations of the biochemical and optical methods. For the first time, this allowed direct studies of MCU activity under highly controlled conditions, such as exact potential across the IMM and exact concentrations for all ions on both sides of the IMM. Importantly, the patch-clamp technique allows for the dissection of single mechanisms involved in mitochondrial $\mathrm{Ca}^{2+}$ transport and allows the characterization of MCU activity at the single organelle level.

Here we applied the patch-clamp technique to compare the properties of $\mathrm{Ca}^{2+}$ currents carried by the MCU in different mouse tissues. This study unexpectedly showed that the density of the MCU current in mouse heart is significantly lower than that in other mouse tissues. Interestingly, the MCU current density in heart was 30 times lower than that in closely related skeletal muscle. This dramatic difference is no likely the result of differences in the molecules responsible for mitochondrial $\mathrm{Ca}^{2+}$ uptake in heart and skeletal muscle, as key biophysical properties of the mitochondrial $\mathrm{Ca}^{2+}$ current in heart and skeletal muscle were the same and correlated well with the biophysical properties of the MCU in COS7 cells ${ }^{18}$.

The very low density of the MCU current in heart was an unexpected finding, as accumulation of $\mathrm{Ca}^{2+}$ into mitochondria in intact cardiac muscle has been previously demonstrated ${ }^{6-8,39}$, and mitochondrial $\mathrm{Ca}^{2+}$ uptake in metabolically active tissues such as heart is perceived as important for the stimulation of mitochondrial ATP production and matching its rate with cytosolic $\mathrm{Ca}^{2+}$ activity ${ }^{7,8,10}$. The paradoxically low MCU activity in heart, however, can be explained if we consider that mitochondria occupy up to $37 \%$ of the total cell volume in heart ${ }^{40}$. If these many heart mitochondria possessed a high ability to accumulate $\mathrm{Ca}^{2+}$, they could abolish the cytosolic $\mathrm{Ca}^{2+}$ signalling necessary for heart contractile activity. Furthermore, because heart is characterized by frequent elevations of cytosolic $\mathrm{Ca}^{2+}$, robust mitochondrial $\mathrm{Ca}^{2+}$ uptake would lead to extensive futile cycling of $\mathrm{Ca}^{2+}$ across the IMM, resulting in low metabolic efficiency. Finally, the frequent elevation of cytosolic $\mathrm{Ca}^{2+}$ could lead to mitochondrial $\mathrm{Ca}^{2+}$ overload and dysfunction. Therefore, in heart, with its abundant mitochondria and frequent elevations in cytosolic $\mathrm{Ca}^{2+}$, it may be essential to 
a

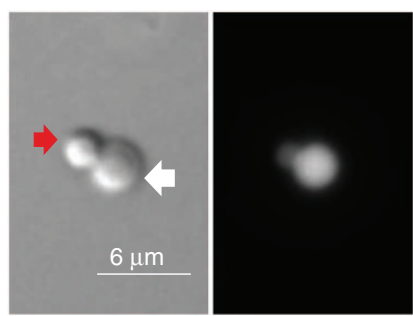

b
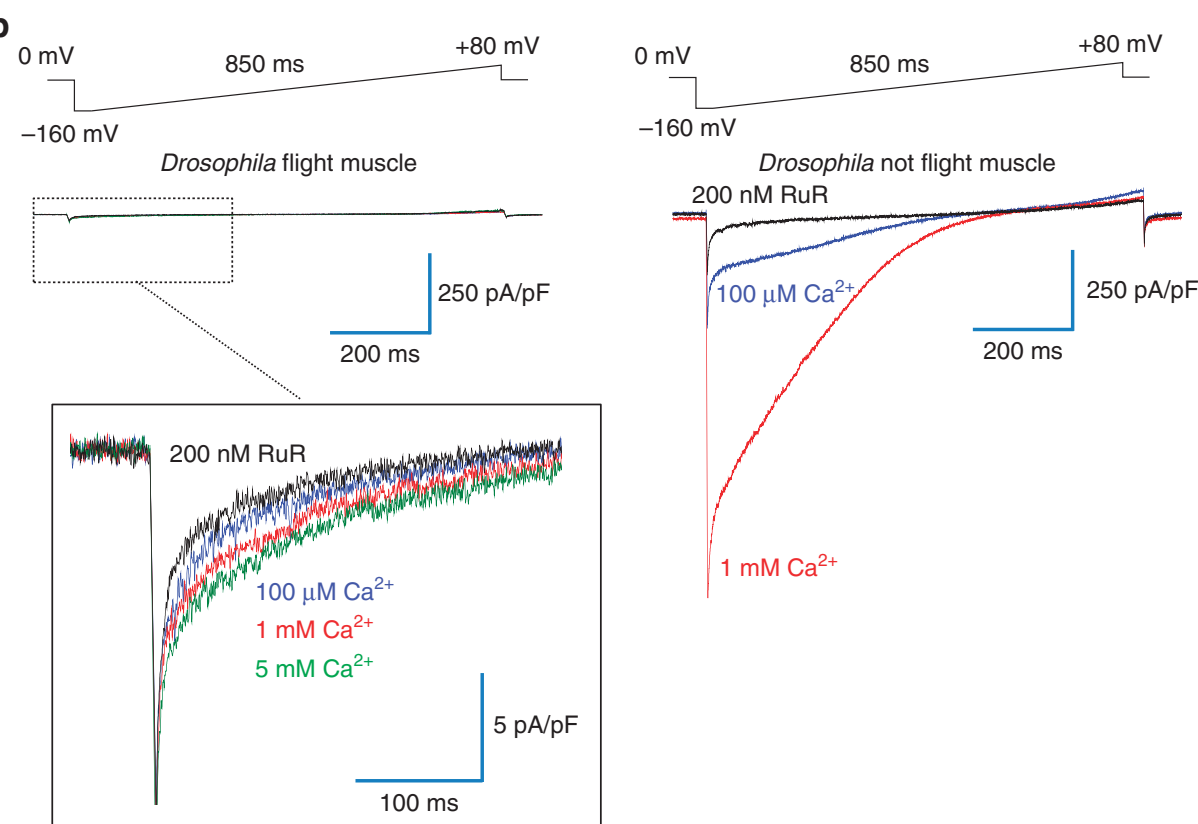

C
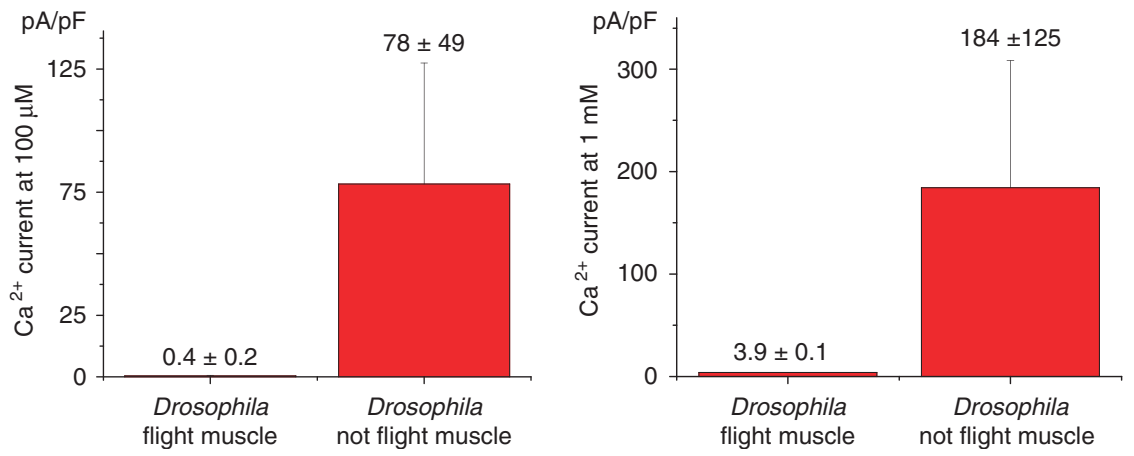

Figure 7 | Mitochondrial $\mathbf{C a}^{2}+$ conductance in Drosophila flight muscle. (a) Representative transmitted left) and fluorescent (right) image of a French press-derived mitoplast isolated from flies expressing GFP targeted to the mitochondrial matrix of the flight muscle (Mef2 > MitoGFP). Note the figure 8-shaped form of the mitoplast. The lobe of the mitoplast containing only the IMM is less dense (white arrow) and clearly distinguishable from the lobe

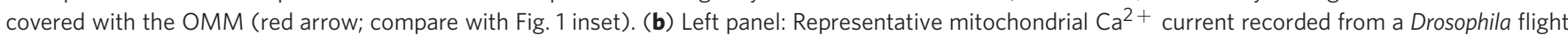
muscle mitoplast in different concentrations of bath $\mathrm{Ca}^{2+}: 5 \mathrm{mM}$ (green), $1 \mathrm{mM}$ (red) and $100 \mu \mathrm{M}$ (blue), and $5 \mathrm{mM} \mathrm{Ca}{ }^{2+}$ plus $200 \mathrm{nM} \mathrm{RuR} \mathrm{(black).}$ Voltage-ramp protocol is indicated on top. Right panel: Representative mitochondrial $\mathrm{Ca}^{2+}$ current recorded from a Drosophila not flight muscle mitoplast in the presence of different concentrations of $\mathrm{Ca}^{2+}$ in the bath: $1 \mathrm{mM}$ (red) and $100 \mu \mathrm{M}$ (blue), and $1 \mathrm{mM} \mathrm{Ca}{ }^{2}+$ plus $200 \mathrm{nM}$ RuR (black). (c) Left panel: Histogram comparing average densities of Drosophila mitochondrial $\mathrm{Ca}^{2}+$ current at $100 \mu \mathrm{M}$ in flight muscle $(n=8)$ and not flight muscle tissues $(n=3)$. Right panel: Histogram comparing average densities of Drosophila mitochondrial $\mathrm{Ca}^{2}+$ current at $1 \mathrm{mM}$ in flight muscle $(n=21)$ and not flight muscle tissues $(n=6)$. Current amplitudes were measured at $5 \mathrm{~ms}$ after stepping the membrane from 0 to $-160 \mathrm{mV}$ (see the voltage protocol). Statistical data are represented as mean \pm s.e.m.

limit MCU activity to preserve both a normal $\mathrm{Ca}^{2+}$-dependent heartbeat and mitochondrial integrity. In contrast, because skeletal muscle mitochondria occupy only about $5 \%$ of the cell volume $^{41,42}$ and are not exposed to frequent $\mathrm{Ca}^{2+}$ elevations, limiting MCU activity in this tissue might not be necessary. It must be noted that although singular heart mitochondria have a limited ability to uptake $\mathrm{Ca}^{2+}$, their abundance can result in combined $\mathrm{Ca}^{2}+$ accumulation comparable to other tissues.

Interestingly, the density of the MCU current in cardiac mitoplasts isolated from newborn mice was about five times larger than that of adult mice. This demonstrates that the MCU activity can vary significantly not only between tissues but also 


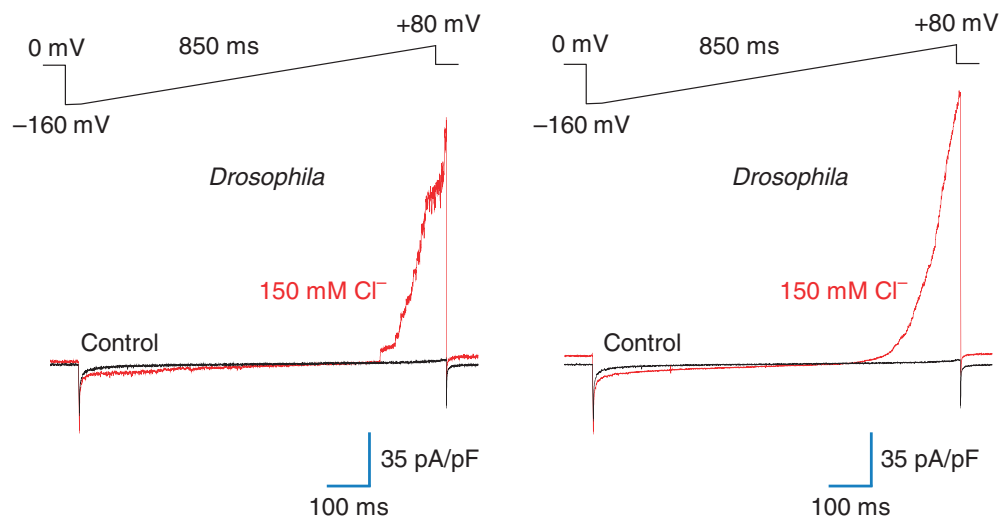

Figure 8 | $\mathbf{~ C l}^{-}$current of the IMM of Drosophila flight muscle. Left panel: representative whole-mitoplast current recorded from Drosophila flight muscle before (black traces) and after (red traces) application of $150 \mathrm{mM} \mathrm{Cl}^{-}$to the bath solution. Pipette solution contained $2 \mathrm{mM} \mathrm{Cl}^{-}$. Currents were elicited by a voltage-ramp protocol (shown above). The whole-mitoplast $\mathrm{Cl}^{-}$current was normalized to the membrane capacitance $\left(C_{\mathrm{m}}\right)$. Right panel: Same experiment as in left panel, but the traces represent an average of 10-20 original current traces to smooth out fluctuations of the outward $\mathrm{Cl}^{-}$current mediated by a large-conductance channel.

during development. Important morphological changes occur during the first week after birth in cardiac myocytes, and the SR and mitochondrial networks are extensively remodeled ${ }^{7}$. In particular, mitochondrial volume density increases from about $20 \%$ in newborn to about $40 \%$ adults ${ }^{43,44}$. The age-related differences in the $\mathrm{Ca}^{2+}$ conductance of the cardiac IMM reported here, together with the morphological changes in SR and mitochondrial network, may explain why beat-to-beat oscillations of mitochondrial $\mathrm{Ca}^{2}+$ are usually observed in newborn and less often in adult cardiomyocytes ${ }^{7,8}$.

Drosophila flight muscle is characterized by even higher $\mathrm{Ca}^{2+}$ -dependent contractile activity than mouse heart, and mitochondria in this tissue occupy about $40 \%$ of the cell volume $e^{45,46}$. Therefore, it is not surprising that the MCU current density in Drosophila flight muscle is about four times lower than that in mouse heart. However, some mitoplasts originating from Drosophila tissues other than flight muscle have very high MCU current density, even exceeding the maximal MCU current density found in mice. Thus, in Drosophila, as seen in mice, MCU activity varies dramatically between tissues.

Whether variations in MCU activity are due to tissue-specific regulation of the MCU (for example, via auxiliary subunits) or to different tissue-specific expression of the MCU channel requires further investigation. However, the tight control of MCU activity in highly active cells with intensive cytosolic $\mathrm{Ca}^{2+}$ signalling is likely crucial for the normal physiology of these cells and for the integrity of their mitochondria. Misregulation of MCU activity in such tissues may lead to derangement of intracellular $\mathrm{Ca}^{2+}$ signalling and mitochondrial dysfunction, followed by functional incompetence and degeneration.

\footnotetext{
Methods

Isolation of mouse mitoplasts for patch-clamp recordings. Mitoplasts were prepared from heart, skeletal muscle, liver, kidney and brown fat of adult (3-6week-old) mice. Mitoplasts were isolated from wild-type C56BL/6 mice, except for brown fat mitoplasts obtained from mice deficient for uncoupling protein 1 (UCP1 - / - C56BL/6 background, courtesy of Dr. Leslie Kozak, Pennington Biomedical Research Center, Louisiana State University, Baton Rouge, Louisiana, USA). Mice were killed by $\mathrm{CO}_{2}$ asphyxiation followed by cervical dislocation. The selected mouse tissue was isolated, rinsed and homogenized in ice-cold medium containing $250 \mathrm{mM}$ sucrose, $10 \mathrm{mM}$ HEPES, and $1 \mathrm{mM}$ EGTA (pH adjusted to 7.25 with $\mathrm{KOH}$ ), using a glass grinder with six slow strokes of a Teflon pestle rotating at 280 (soft tissues) or 600 (fibrous tissues) rotations per minute. The homogenate was centrifuged at $700 \mathrm{~g}$ for 5-10 min to pellet nuclei and unbroken cells. For some tissues, the first nuclear pellet was resuspended in the same solution and homogenized again to increase the yield of mitochondria. Mitochondria were collected
}

by centrifugation of the supernatant at $8,500 \mathrm{~g}$ for $10 \mathrm{~min}$. Mitoplasts were produced from mitochondria using a French press. Briefly, mitochondria were suspended in a solution containing $140 \mathrm{mM}$ sucrose, $440 \mathrm{mM}$ D-mannitol, $5 \mathrm{mM}$ HEPES, and $1 \mathrm{mM}$ EGTA (pH adjusted to 7.2 with $\mathrm{KOH}$ ), and then subjected to a French press at 2,000 psi to rupture the outer membrane. Mitoplasts were pelleted at $10,500 \mathrm{~g}$ for $15 \mathrm{~min}$ and resuspended for storage in $500 \mu \mathrm{l}$ of solution containing $750 \mathrm{mM} \mathrm{KCl}, 100 \mathrm{mM}$ HEPES and $1 \mathrm{mM}$ EGTA (pH adjusted to 7.2 with $\mathrm{KOH}$ ). Mitochondria and mitoplasts were prepared at $0-4^{\circ} \mathrm{C}$ and stored on ice for up to $5 \mathrm{~h}$. The French press method allows for a more gentle mechanical isolation of mitoplasts, and the pressure applied can be controlled to preserve the cristae of mitoplasts ${ }^{29}$

Immediately before the electrophysiological experiments, $15-50 \mu \mathrm{l}$ of the mitoplast suspension was added to $500 \mu \mathrm{l}$ of a solution containing $150 \mathrm{mM} \mathrm{KCl}$, $10 \mathrm{mM}$ HEPES and $1 \mathrm{mM}$ EGTA (pH adjusted to 7.2 with $\mathrm{KOH}$ ), and plated on 5 -mm coverslips. For whole-mitoplast experiments, coverslips were pretreated with $0.1 \%$ gelatin to reduce adhesion. Only mitoplasts that had a figure 8 -shaped appearance were selected for experiments, as this indicated the integrity of the matrix and membranes (Fig. 1).

Isolation of Drosophila mitoplasts. The upstream activating sequenceMitoGFP $^{47,48}$ and Mef2-Gal4 (refs 47,49) flies were used as previously described. Flies were raised at $25^{\circ} \mathrm{C}$, and adult flies $>5$ days of age after eclosion were used. Drosophila mitoplasts were obtained from either the combined thoraces (devoid of legs and wings) of 70 flies or 30-50 whole-bodies of the Mef2 $>$ MitoGFP flies. After grinding thoraces/whole flies with a Politron homogenizer for $3 \mathrm{~min}$ (rheostat set at 4), mitoplasts were obtained with the same protocol used for mouse mitoplasts (see above). Note that French-pressed Drosophila mitoplasts maintained the same figure 8-shaped morphology as seen in mouse mitoplasts (compare Figs $7 \mathrm{a}$ and 1 inset, white arrows).

Patch-clamp recordings. Mouse or Drosophila mitoplasts $(2-6 \mu \mathrm{m}$ in size) were used for patch-clamp experiments and typically had membrane capacitances of 0.3-1.3 pF. Currents were recorded using an Axopatch 200B amplifier (Molecular Devices). The voltage protocols and recording conditions are as indicated in the figures. Mitoplasts were stimulated every $5 \mathrm{~s}$. To minimize errors in the voltage clamp associated with the liquid junction potential, a 3-M KCl-agar salt bridge was used as the bath reference electrode. Gigaohm seals with mitoplasts were formed in the bath solution containing $150 \mathrm{mM} \mathrm{KCl}, 10 \mathrm{mM}$ HEPES and $1 \mathrm{mM}$ EGTA, pH 7.2 (adjusted with $\mathrm{KOH}$ ). Capacitative transients were completely compensated right after the seal was formed. Voltage steps of $350-500 \mathrm{mV}$ from $15-50 \mathrm{~ms}$ were applied to rupture the IMM and obtain the whole-mitoplast configuration, as monitored by the appearance of capacitance transients and an increase in baseline noise.

The access resistance and membrane capacitance of mitoplasts were determined using the Membrane Test tool of pClamp 10 (Molecular Devices). Typically, pipettes had resistances of 30-50 M 2 , and the access resistance was $40-80 \mathrm{M} \Omega$. The averaged membrane capacitance of mitoplasts used in our experiments varied between tissues and was $(0.65 \pm 0.04 \mathrm{pF}, n=40)$ for skeletal muscle, $(0.68 \pm 0.04 \mathrm{pF}$, $n=13)$ for brown fat, $(0.54 \pm 0.02 \mathrm{pF}, n=18)$ for kidney, $(0.36 \pm 0.02 \mathrm{pF}, n=19)$ for liver, $(0.67 \pm 0.02 \mathrm{pF}, n=55)$ for heart and $(1.31 \pm 0.06 \mathrm{pF}, n=54)$ for Drosophila flight muscle. The calculated voltage clamp errors associated with the access resistance never exceeded $10 \mathrm{mV}$. Current amplitudes for histograms were measured within $5 \mathrm{~ms}$ after stepping the membrane from 0 to $-160 \mathrm{mV}$. 
To measure $\mathrm{Ca}^{2+}$ currents through the MCU, Figs 1-3, 5 and 6, pipettes were filled with $150 \mathrm{mM}$ tetramethylammonium hydroxide, $1.5 \mathrm{mM}$ EGTA, $1 \mathrm{mM}$ $\mathrm{MgCl}_{2}$ (2 $\mathrm{mM} \mathrm{MgCl}_{2}$ for Drosophila), and $150 \mathrm{mM}$ HEPES, pH 7.0 with D-gluconic acid, tonicity $450 \mathrm{mmol}$ per $\mathrm{kg}(\sim 330 \mathrm{mmol}$ per $\mathrm{kg}$ for Drosophila $)$ with sucrose. In some experiments for Drosophila recordings, the tetramethylammonium hydroxide pipette solution was replaced with $110 \mathrm{mM}$ Na-gluconate, $40 \mathrm{mM}$ HEPES, $1.5 \mathrm{mM}$ EGTA and $2 \mathrm{mM} \mathrm{NaCl}$ (pH adjusted to 7.0 with $\mathrm{NaOH}$, tonicity adjusted to $\sim 330 \mathrm{mmol}$ per $\mathrm{kg}$ with sucrose). Whole-mitoplast control currents in Figs 1-3a, 5, were recorded in a bath solution (HEPES/Tris solution) containing $150 \mathrm{mM}$ HEPES and $1 \mathrm{mM}$ EGTA (pH adjusted to 7.0 with Tris-base, tonicity adjusted to $\sim 300 \mathrm{mmol}$ per $\mathrm{kg}$ with sucrose). To record whole-mitoplast $I_{\mathrm{MCU}}$ $\mathrm{Ca}^{2+}$ currents (Figs 1-3,5 and 6), a 1-M CaCl stock solution was diluted to the final desired concentration in the HEPES/Tris solution without EGTA. To block $I_{\mathrm{MCU}} \mathrm{Ca}^{2+}$ currents, RuR was added to the $100-\mu \mathrm{M} \mathrm{Ca}^{2+}$ bath solution at a final concentration of $50 \mathrm{nM}$ (Fig. $7 \mathrm{a}$ ) or to the $1-5 \mathrm{mM} \mathrm{Ca}^{2+}$ bath solution at a final concentration of $200 \mathrm{nM}$ (left and right panels of Fig. 7b). Bath solutions containing $100 \mu \mathrm{M}-1 \mathrm{mM} \mathrm{Ba}^{2+}$ or $\mathrm{Mg}^{2+}$ were obtained by the addition of a 1-M stock solution of the corresponding chloride salt into the HEPES-Tris solution without EGTA.

To study the monovalent current carried by MCU in DVF conditions (Fig. 5), the following pipette solution was used: $110 \mathrm{mM}$ Na-gluconate, $40 \mathrm{mM}$ HEPES, $1 \mathrm{mM}$ EGTA, $5 \mathrm{mM}$ EDTA and $2 \mathrm{mM} \mathrm{NaCl}$ (pH adjusted to 7.0 with $\mathrm{NaOH}$, tonicity adjusted to $\sim 450 \mathrm{mmol}$ per $\mathrm{kg}$ with sucrose). Bath solution used for these experiments contained: $110 \mathrm{mM}$ Na-gluconate, $40 \mathrm{mM}$ HEPES, $1 \mathrm{mM}$ EGTA and 5 mM EDTA (pH 7.0 with $\mathrm{NaOH}$, tonicity adjusted to $300 \mathrm{mmol}$ per $\mathrm{kg}$ with sucrose). $\mathrm{CaCl}_{2}$ was added to the Na-gluconate bath solution in the amount calculated by the MaxChelator winMaxC v2.05 programme (C. Patton, Stanford University) to obtain various free concentrations of $\mathrm{Ca}^{2+}$ in the nanomolar range (Fig. 4a). For experiments in which we studied the permeability of the MCU to $\mathrm{K}^{+}$in the DVF conditions (Fig. 4c), the following bath solution was employed: $110 \mathrm{mM}$ K-gluconate, $40 \mathrm{mM}$ HEPES, $1 \mathrm{mM}$ EGTA and $5 \mathrm{mM}$ EDTA (pH 7.0 with $\mathrm{KOH}$, tonicity adjusted to $300 \mathrm{mmol}$ per $\mathrm{kg}$ with sucrose). All electrophysiological experiments were performed under continuous perfusion of the bath solution.

Data acquisition and analyses were performed using PClamp 10 (Molecular Devices) and Origin 7.5 (OriginLab). All electrophysiological data presented were acquired at $10 \mathrm{kHz}$ and filtered at $1 \mathrm{kHz}$. Statistical data are presented as the mean \pm s.e.

All general chemicals as were purchased from Sigma (USA).

\section{References}

1. Duchen, M. R. Contributions of mitochondria to animal physiology: from homeostatic sensor to calcium signalling and cell death. J. Physiol. 516(Pt 1): 1-17 (1999).

2. Carafoli, E. Calcium signaling: a tale for all seasons. Proc. Natl Acad. Sci. USA 99, 1115-1122 (2002)

3. Carafoli, E. The interplay of mitochondria with calcium: An historical appraisal. Cell Calcium 52, 1-8 (2012).

4. McCormack, J. G., Halestrap, A. P. \& Denton, R. M. Role of calcium ions in regulation of mammalian intramitochondrial metabolism. Physiol. Rev. 70, 391-425 (1990)

5. Hajnoczky, G., Robb-Gaspers, L. D., Seitz, M. B. \& Thomas, A. P. Decoding of cytosolic calcium oscillations in the mitochondria. Cell 82, 415-424 (1995).

6. Robert, V. et al. Beat-to-beat oscillations of mitochondrial $\left[\mathrm{Ca}^{2+}\right]$ in cardiac cells. EMBO J. 20, 4998-5007 (2001).

7. Griffiths, E. J., Balaska, D. \& Cheng, W. H. The ups and downs of mitochondrial calcium signalling in the heart. Biochim. Biophys. Acta. 1797, 856-864 (2010).

8. Dedkova, E. N. \& Blatter, L. A. Mitochondrial $\mathrm{Ca}^{2+}$ and the heart. Cell Calcium 44, 77-91 (2008).

9. Nicholls, D. G. Mitochondrial calcium function and dysfunction in the central nervous system. Biochim. Biophys. Acta. 1787, 1416-1424 2009.

10. Rizzuto, R., Bernardi, P. \& Pozzan, T. Mitochondria as all-round players of the calcium game. J. Physiol. 529(Pt 1): 37-47 (2000).

11. Carafoli, E., Patriarca, P. \& Rossi, C. S. A comparative study of the role of mitochondria and the sarcoplasmic reticulum in the uptake and release of $\mathrm{Ca}^{2+}$ by the rat diaphragm. J. Cell. Physiol. 74, 17-30 (1969).

12. Rudolf, R., Mongillo, M., Magalhaes, P. J. \& Pozzan, T. In vivo monitoring of $\mathrm{Ca}^{2+}$ uptake into mitochondria of mouse skeletal muscle during contraction. J. Cell. Biol. 166, 527-536 (2004).

13. Quintana, A. \& Hoth, M. Mitochondrial dynamics and their impact on T cell function. Cell Calcium 52, 57-63 (2012).

14. Halestrap, A. P. Calcium, mitochondria and reperfusion injury: a pore way to die. Biochem. Soc. Trans. 34, 232-237 (2006).

15. Pacher, P. \& Hajnoczky, G. Propagation of the apoptotic signal by mitochondrial waves. EMBO J. 20, 4107-4121 (2001).

16. Carafoli, E. Intracellular calcium homeostasis. Annu. Rev. Biochem. 56, 395-433 (1987).

17. Gunter, T. E. \& Pfeiffer, D. R. Mechanisms by which mitochondria transport calcium. Am. J. Physiol. 258, C755-C786 (1990).
18. Kirichok, Y., Krapivinsky, G. \& Clapham, D. E. The mitochondrial calcium uniporter is a highly selective ion channel. Nature 427, 360-364 (2004).

19. De Stefani, D., Raffaello, A., Teardo, E., Szabo, I. \& Rizzuto,

R. A forty-kilodalton protein of the inner membrane is the mitochondrial calcium uniporter. Nature 476, 336-340 (2011).

20. Baughman, J. M. et al. Integrative genomics identifies MCU as an essential component of the mitochondrial calcium uniporter. Nature 476, 341-345 (2011).

21. Perocchi, F. et al. MICU1 encodes a mitochondrial EF hand protein required for $\mathrm{Ca}^{2+}$ uptake. Nature 467, 291-296 (2010).

22. Mallilankaraman, K. et al. MICU1 is an essential gatekeeper for MCU-mediated mitochondrial $\mathrm{Ca}(2+)$ uptake that regulates cell survival. Cell 151, 630-644 (2012).

23. Bernardi, P. Mitochondrial transport of cations: channels, exchangers, and permeability transition. Physiol. Rev. 79, 1127-1155 (1999).

24. Rizzuto, R., Simpson, A. W., Brini, M. \& Pozzan, T. Rapid changes of mitochondrial $\mathrm{Ca} 2+$ revealed by specifically targeted recombinant aequorin. Nature 358, 325-327 (1992).

25. Pozzan, T. \& Rudolf, R. Measurements of mitochondrial calcium in vivo. Biochim. Biophys. Acta. 1787, 1317-1323 (2009).

26. Nicholls, D. G. Calcium transport and porton electrochemical potential gradient in mitochondria from guinea-pig cerebral cortex and rat heart. Biochem. J. 170, 511-522 (1978).

27. Chalmers, S. \& Nicholls, D. G. The relationship between free and total calcium concentrations in the matrix of liver and brain mitochondria. J. Biol. Chem. 278, 19062-19070 (2003)

28. Brookes, P. S. et al. UCPs-unlikely calcium porters. Nat. Cell. Biol. 10, 1235-1237 (2008).

29. Decker, G. L. \& Greenawalt, J. W. Ultrastructural and biochemical studies of mitoplasts and outer membranes derived from French-pressed mitochondria. Advances in mitochondrial subfractionation. J. Ultrastruct. Res. 59, 44-56 (1977).

30. Sorgato, M. C., Keller, B. U. \& Stuhmer, W. Patch-clamping of the inner mitochondrial membrane reveals a voltage-dependent ion channel. Nature 330, 498-500 (1987).

31. Borecky, J., Jezek, P. \& Siemen, D. 108-pS channel in brown fat mitochondria might Be identical to the inner membrane anion channel. J. Biol. Chem. 272, 19282-19289 (1997).

32. Garlid, K. D. \& Beavis, A. D. Evidence for the existence of an inner membrane anion channel in mitochondria. Biochim. Biophys. Acta. 853, 187-204 (1986).

33. Drahota, Z., Gazzotti, P., Carafoli, E. \& Rossi, C. S. A comparison of the effects of different divalent cations on a number of mitochondrial reactions linked to ion translocation. Arch. Biochem. Biophys. 130, 267-273 (1969).

34. Vainio, H., Mela, L. \& Chance, B. Energy dependent bivalent cation translocation in rat liver mitochondria. Eur. J. Biochem. 12, 387-391 (1970).

35. Hille, B. Ionic Channels Of Excitable Membranes 2nd edn (Sinauer Associates, 1992).

36. von Stockum, S. et al. Properties of $\mathrm{Ca}(2+)$ transport in mitochondria of Drosophila melanogaster. J. Biol. Chem. 286, 41163-41170 (2011).

37. Deluca, H. F. \& Engstrom, G. W. Calcium uptake by rat kidney mitochondria. Proc. Natl Acad. Sci. USA 47, 1744-1750 (1961).

38. Vasington, F. D. \& Murphy, J. V. Ca ion uptake by rat kidney mitochondria and its dependence on respiration and phosphorylation. J. Biol. Chem. 237, 2670-2677 (1962).

39. Maack, C. et al. Elevated cytosolic $\mathrm{Na}^{+}$decreases mitochondrial $\mathrm{Ca}^{2}+$ uptake during excitation-contraction coupling and impairs energetic adaptation in cardiac myocytes. Circ. Res. 99, 172-182 (2006).

40. Barth, E., Stammler, G., Speiser, B. \& Schaper, J. Ultrastructural quantitation of mitochondria and myofilaments in cardiac muscle from 10 different animal species including man. J. Mol. Cell. Cardiol. 24, 669-681 (1992).

41. Drexler, H. et al. Alterations of skeletal muscle in chronic heart failure. Circulation 85, 1751-1759 (1992).

42. Hoppeler, H. \& Fluck, M. Plasticity of skeletal muscle mitochondria: structure and function. Med. Sci. Sports Exerc. 35, 95-104 (2003).

43. Olivetti, G., Anversa, P., Melissari, M. \& Loud, A. V. Morphometric study of early postnatal development of the thoracic aorta in the rat. Circ. Res. 47, 417-424 (1980).

44. Legato, M. J. Cellular mechanisms of normal growth in the mammalian heart II. A quantitative and qualitative comparison between the right and left ventricular myocytes in the dog from birth to five months of age. Circ. Res. 44, 263-279 (1979).

45. Magwere, T. et al. The effect of dietary restriction on mitochondrial protein density and flight muscle mitochondrial morphology in Drosophila. J. Gerontol. A. Biol. Sci. Med. Sci. 61, 36-47 (2006). 
46. Suarez, R. K., Lighton, J. R., Brown, G. S. \& Mathieu-Costello, O. Mitochondrial respiration in hummingbird flight muscles. Proc. Natl Acad. Sci. USA 88, 4870-4873 (1991).

47. Park, J. et al. Mitochondrial dysfunction in Drosophila PINK1 mutants is complemented by parkin. Nature 441, 1157-1161 (2006).

48. Verstreken, P. et al. Synaptic mitochondria are critical for mobilization of reserve pool vesicles at Drosophila neuromuscular junctions. Neuron 47, 365-378 (2005).

49. Ranganayakulu, G. et al. A series of mutations in the D-MEF2 transcription factor reveal multiple functions in larval and adult myogenesis in Drosophila. Dev. Biol. 171, 169-181 (1995).

\section{Acknowledgements}

This work was funded by the NIH Director's New Innovator Award DP2OD004656-01.

\section{Author contributions}

F.F. and Y.K. conceived the project, designed the experiments, and wrote the manuscript. F.F. performed all electrophysiological experiments. S.B.L. and Y.N.J. generated the Drosophila line expressing mitochondria GFP in the flight muscle. All authors discussed the results and commented on the manuscript.

\section{Additional information}

Competing financial interests: The authors declare no competing financial interests.

Reprints and permission information is available online at http://npg.nature.com/ reprintsandpermissions/

How to cite this article: Fieni, F. et al. Activity of the Mitochondrial Calcium Uniporter Varies Greatly between Tissues. Nat. Commun. 3:1317 doi: 10.1038/ncomms2325 (2012). 